\title{
Analisis Pemberdayaan Perempuan Melalui Simpan Pinjam Kelompok
}

\author{
Ardiyati* \\ Prodi Ilmu Pemerintahan, Universitas AMIKOM Yogyakarta, Indonesia \\ Diterima Februari 2018; Disetujui April 2018; Dipublikasikan Juni 2018
}

\begin{abstract}
Abstrak
Salah satu model simpan pinjam kelompok perempuan adalah Kegiatan Simpan Perempuan terintegrasi dalam Program PNPM Mandiri Pedesaan yang resmi berakhir pada tahun 2014. Disisi lain kegiatan simpan pinjam kelompok perempuan memiliki sumber kekayaan bernilai ratusan juta dan menjadi salah satu lembaga simpan pinjam yang dibutuhkan usaha kecil. Penelitian ini bertujuan untuk mengetahui sejauhmana hasil-hasil pemberdayaan kegiatan simpan pinjam kelompok perempuan terutama di Kecamatan Pajangan, Kabupaten Bantul, Provinsi Yogyakarta. Metode penelitian adalah campuran kualitatif dan kuantitatif. Hasil penelitian menunjukkan kegiatan pemberdayaan perempuan terjadi perubahan kemampuan ekonomi anggota menjadi bisa mempunyai uang dan tidak terlalu bergantung pada suami. Kegiatan juga mengubah sebagian besar anggota dari buruh menjadi mempunyai usaha sendiri, dan mayoritas usaha masih dikelola sendiri. Terjadi peningkatan partisipasi responden pada pembangunan di tingkat dusun, kecamatan, dan kabupaten tetapi tidak di tingkat RT. Peningkatan kemampuan perempuan dalam pengelolaan usaha meningkat dari buruh menjadi memiliki usaha. Fasilitas pelatihan peningkatan usaha terbatas dinikmati sebagian kecil anggota terutama pengurus kelompok. Perlunya pelembagaan UPK menjadi lembaga berbadan hukum.. Bentuk lembaga yang cocok dengan visi pengentasan kemiskinan adalah koperasi ataupun Badan Usaha Milik Desa (BUMDES).
\end{abstract}

Kata Kunci : pemberdayaan. Simpan pinjam, kelompok perempuan

\begin{abstract}
One models of group savings and loan activities is the Savings Activity of Women with PNPM Mandiri Rural Program conducted in 2014. On the other side of the savings and loan activities of women groups that exist today. This study aims to find out about the results of the empowerment of activities undertaken in Pajangan, Bantul Regency, Yogyakarta Province. The research method is quantitative and quantitative. The results show empowerment activities conducted by people who are able to make money and not very profitable to the husband. The activities also changed most of the members from work to being selfemployed, and the great struggle was still self-managing. Increasing the level of participation of respondents at hamlet, sub-district and district levels but not at the RT level. Improve the ability of women in managing the business from becoming a company. Training facilities are limited to limited members. Perlun institutionalization of the UPK become a legal body .. The form of institutions that fit with the vision of poverty alleviation is a cooperative or Village Owned Enterprises (BUMDES).
\end{abstract}

Keywords: empowerment, save and loan, female group

How to Cite : Ardiyati (2018). Analisis Pemberdayaan Perempuan Melalui Simpan Pinjam Kelompok 6 (1): 91-99

${ }^{*}$ Corresponding author: P-ISSN-2549-9165

E-mail: ardiyati@gmail.com e-ISSN -2580-2011 
PENDAHULUAN

Kemiskinan menurut Emil (dalam Suyanto, 1996:11) adalah kurangnya pendapatan untuk memenuhi hidup. Pengentasan kemiskinan menjadi prioritas utama dalam pembangunan dan selalu dipantau perkembangannya dari tahun ke tahun. Badan Pusat Statistik Indonesia mendefinisikan kemiskinan sebagai ketidak mampuan dari sisi ekonomi untuk memenuhi kebutuhan dasar makanan dan bukan makanan yang diukur dari sisi pengeluaran. Suryadharma (dalam Kuncoro,2008:4) berpendapat bahwa pemberdayaan UMKM merupakan mekanisme efektif untuk menanggulangi kemiskinan, pengangguran, dan penciptaan lapangan kerja.

Pemberdayaan perempuan dalam konteks kebijakan sesuai dengan Inpres No 9/2000 tentang pengarusutamaan gender yaitu kebijakan dapat mengintegrasikan pengalaman, kebutuhan dan perempuan dan laki-laki ke dalam proses perencanaan, pelaksanaan, pemantauan dan evaluasi kebijakan, program, peraturan serta anggaran dalam segala bidang (politik, ekonomi, sosial budaya, hukum, pertahanan, keamanan dan kemasyarakatan). Ini berarti pemberdayaan perempuan harus terintegrasi antara pemberdayaan ekonomi dan kebijakan bagi perempuan. Keberhasilan pemberdayaan (Sedarmayanti, 2004:146) bahwa indikator keberhasilan pemberdayaan terhadap perempuan adalah:
1) Meningkatnya kemampuan kaum perempuan untuk melibatkan diri dalam pembangunan,

2) Program pembangunan, sebagai partisipan aktif (subyek) agar tidak sekedar menjadi obyek pembangunan,

3) Meningkatkan kaum perem puan untuk melibatkan diri dalam kepemimpinan untuk meningkatkan posisi tawar-menawar dan keterlibatan dalam setiap program pembangunan, baik perencana, pelaksana, maupun pemantauan dan evaluasi kegiatan,

4) Meningkatkan kemampuan kaum perempuan dalam mengelola usaha skala rumah tangga, industry kecil maupun besar untuk menunjang kebutuhan rumah tangga, maupun untuk membuka peluang kerja produktif dan mandiri.

5) Meningkatkan peran dan fungsi organisasi perempuan di tingkat lokal sebagai wadah pemberdayaan kaum perempuan agar dapat terlibat secara aktif dalam program pembangunan pada wilayah tempat tinggalnya.

Sulitnya akses permodalan usaha mikro mendorong munculnya kredit mikro. Grameen Banking (Wardoyo dan Prabowo, 2005:3) mendefinisikan kredit mikro sebagai pengembangan pinjaman dalam jumlah kecil kepada pengusaha yang terlalu lemah kualifikasinya untuk dapat mengakses pada pinjaman bank tradisional. Pendekatan anti kemiskinan dalam kerangka perempuan dalam 
pembangunan menempatkan perempuan sebagai kelompok the poorest of the poor. Beberapa pendapat bahkan mengatakan rumah tangga yang dikepalai perempuan sering menjadi kelompok the poorest of the poor. Argumen lain yang lebih rasional tentang mengapa kredit mikro lebih baik ditujukan kepada perempuan, dapat digali dari strategi bertahan hidup perempuan.

Mayoux (dalam asmorowati, 2005) berpendapat bahwa akses terhadap kredit mikro untuk perempuan mempunyai efek penting terhadap proses pemberdayaan perempuan. Indikator keberhasilan pemberdayaan terhadap perempuan yang dikemukakan oleh Sedarmayanti (2004:146) adalah:

1. Meningkatnya kemampuan kaum perempuan untuk melibatkan diri dalam program pembangunan, sebagai partisipan aktif (subyek) agar tidak sekedar menjadi obyek pembangunan,

2. Meningkatkan kaum perempuan untuk melibatkan diri dalam kepemimpinan untuk meningkatkan posisi tawarmenawar dan keterlibatan dalam setiap program pembangunan, baik perencana, pelaksana, maupun pemantauan dan evaluasi kegiatan,

3. Meningkatkkan kemampuan kaum perempuan dalam mengelola usaha skala rumah tangga, industry kecil maupun besar untuk menunjang kebutuhan rumah tangga, maupun untuk membuka peluang kerja produktif dan mandiri,

Meningkatkan peran dan fungsi organisasi perempuan di tingkat lokal sebagai wadah pemberdayaan kaum perempuan agar dapat terlibat secara aktif dalam program pembangunan pada wilayah tempat tinggalnya. Penelitian ini bertujuan untuk mengetahui sejauhmana hasil-hasil kegiatan pemberdayaan perempuan melalui simpan pinjam kelompok. Penelitian juga akan menganalisis tentang keberlanjutan program sampai berakhirnya Program PNPM Mandiri Pedesaan yang merupakan payung kegiatan simpan pinjam kelompok perempuan. Penelitian ini mengambil kasus Pemberdayaan Masyarakat melalui simpan pinjam kelompok di Kecamatan Pajangan, Kabupaten Bantul, Daerah lstimewa Yogyakarta.

\section{Metode Penelitian}

Penelitian dilakukan dengan metode campuran kualitatif dan kuantitatif. Metode kualitatif dengan melakukan wawancara terhadap informan (1) Penanggungjawab Operasional Kecamatan PNPM Mandiri Pedesaan Kecamatan Pajangan, (2) Pengurus Unit Pelaksana Kegiatan/UPK (ketua, sekretaris, bendahara, pendamping lapangan), (3) Badan Pengawas UPK (BPUPK), (4) kelompok-kelompok SPP yang juga diberikan bertanyaan survey. Metode kuantitatif dilakukan melihat efektivitas implementasi kegiatan. Pelaksanaannya 
dengan melakukan survey terhadap 120 sample dari 1.183 jumlah anggota

\section{Hasil dan Pembahasan}

Mayoritas kelompok beranggotakan 6-10 orang. Mayoritas rumah tangga miskin dalam kelompok berjumlah 1-5 orang. Meskipun demikian jumlah 1-5 orang rumah tangga miskin tersebut termasuk

Grafik I Rumah Tangga Miskin yang Tergabung dalam Kelompok

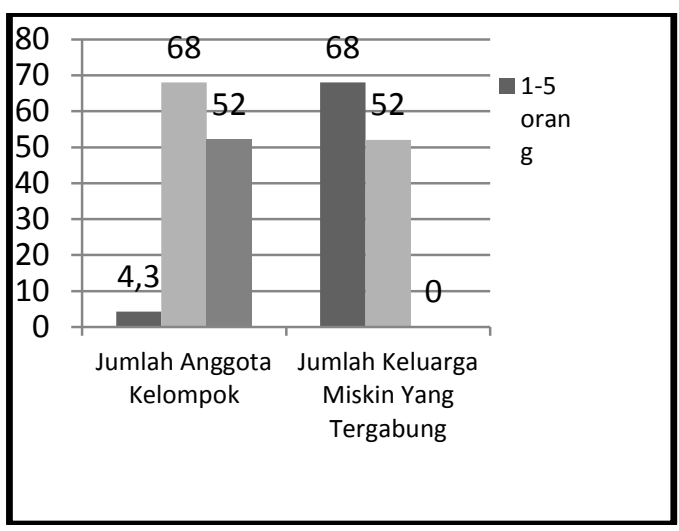

Mayoritas kelompok beranggotakan 6-10 orang dengan jumlah rumah tangga miskin dalam kelompok berjumlah 1-5 orang. Kegiatan SPP PNPM memang tidak mensyaratkan bahwa seluruh anggota kelompok harus merupakan rumah tangga miskin. Dalam sebuah kelompok dipersilahkan memiliki anggota yang mampu dan rumah tangga miskin agar dapat saling mensupport. Penggunaan pinjaman mayoritas digunakan untuk kegiatan usaha sendiri. Sebagian anggota dalam 51-100\% dari jumlah anggota. Kegiatan SPP PNPM memang tidak mensyaratkan bahwa seluruh anggota kelompok harus merupakan rumah tangga miskin. Dalam sebuah kelompok dipersilahkan memiliki anggota yang mampu dan rumah tangga miskin agar dapat saling mensupport.

Grafik 2 Persentase Keluarga Miskin (RTM) dalam Kelompok

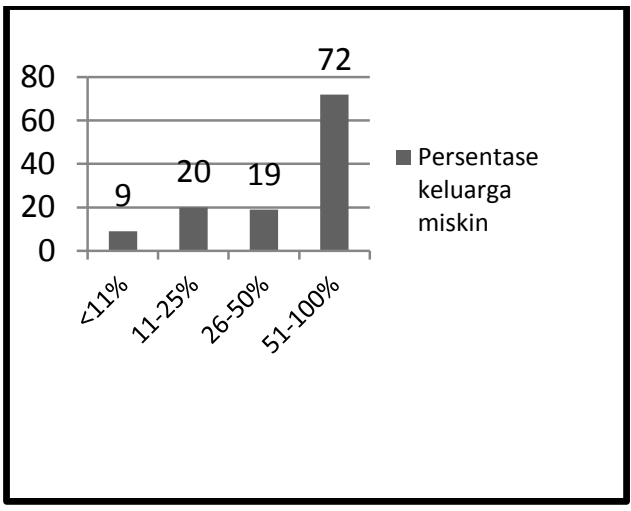

menggunakan uang pinjaman untuk membantu usaha suami, membayar sekolah anak, belanja rumah tangg, dan kegiatan lainnya. Pinjaman untuk kegiatan lainnya sebagian besar digunakan untuk perbaikan rumah. Jumlah pinjaman yang diperoleh masyarakat sebesar minimal 2 juta dianggap sangat besar sehingga digunakan sebaik-baiknya untuk perbaikan rumah pada rumah tangga miskin. 


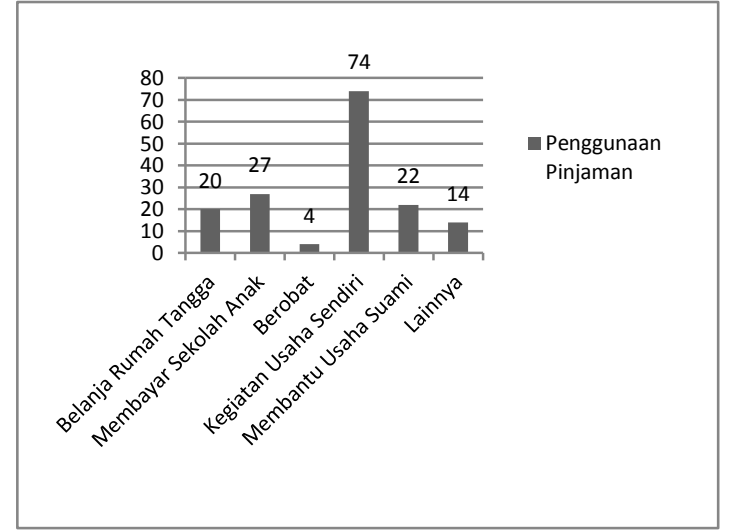

Grafik 4 Penggunaan Pinjaman

Penggunaan pinjaman untuk kegiatan non usaha tidak menyalahi prosedur dalam ketentuan kegiatan simpan pinjam perempuan. Hanya saja dalam pengamatan peneliti, penggunaan pinjaman untuk non usaha terutama untuk berobat, belanja rumah tangga dan kegiatan lain seperti membangun rumah terjadi pada kelompok macet.Penggunaan pinjaman untuk sekolah, berobat dan belanja rumah tangga terjadi pada anggota yang termasuk rumah tangga miskin. Semakin mahalnya Grafik 5 Tenaga Kerja yang Dimiliki

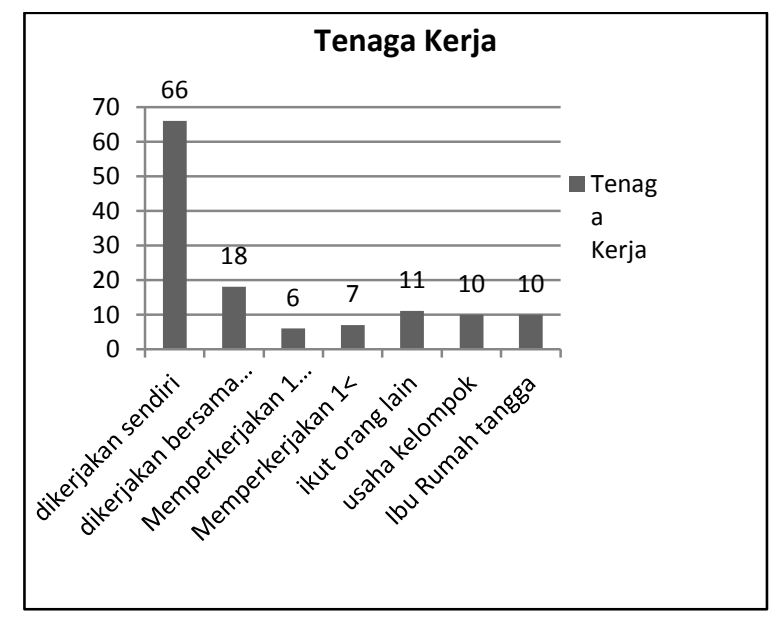

Responden yang masih tetap ikut orang lain dan tidak membuka usaha sendiri berdasarkan pengamatan peneliti responden yang mengalami kegagalan biaya masuk sekolah membuat rumah tangga miskin anggota SPP PNPM bersandar pada pinjaman tanpa agunan kegiatan SPP PNPM. Kondisi ini menunjukkan bahwa keberadaan SPP PNPM untuk kegiatan SPP di Kecamatan Pajangan digunakan oleh rumah tangga miskin untuk kegiatan non usaha seperti biaya berobat, biaya sekolah dan perbaikan rumah. Penggunaan pinjaman untuk modal usaha pada mayoritas anggota masih dikerjakan sendiri dalam mengembangkan usahanya (66 orang), dikerjakan bersama keluarga (18 orang) dan memperkerjakan lebih dari 1 orang pada 7 responden. Usaha yang memiliki tenaga kerja lebih dari 1 orang dengan jenis usaha ternak ayam, kerajinan batik kayu, emping melinjo, katering dan produksi makanan kecil.

Grafik 6 Perubahan Penghasilan

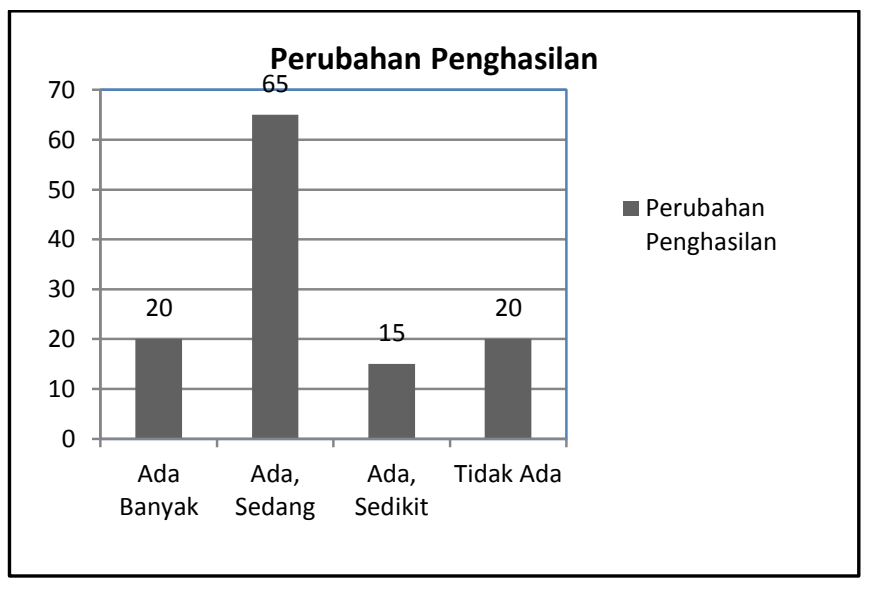

usaha seperti toko kelontong ataupun terjadi penyalahgunaan oleh pengurus sehingga kesulitan melakukan akses pinjaman lagi. Responden yang tidak 
memiliki usaha dan tidak memiliki pekerjaan menggunakan pinjaman untuk kegiatan non usaha seperti pendidikan dana kesehatan. Terkait dengan perubahan penghasilan mayoritas peserta menyatakan perubahan bersifat sedang. Berdasarkan pengamatan peneliti responden yang

Grafik 10 Partisipasi Anggota dalam kegiatan selain Simpan Pinjam

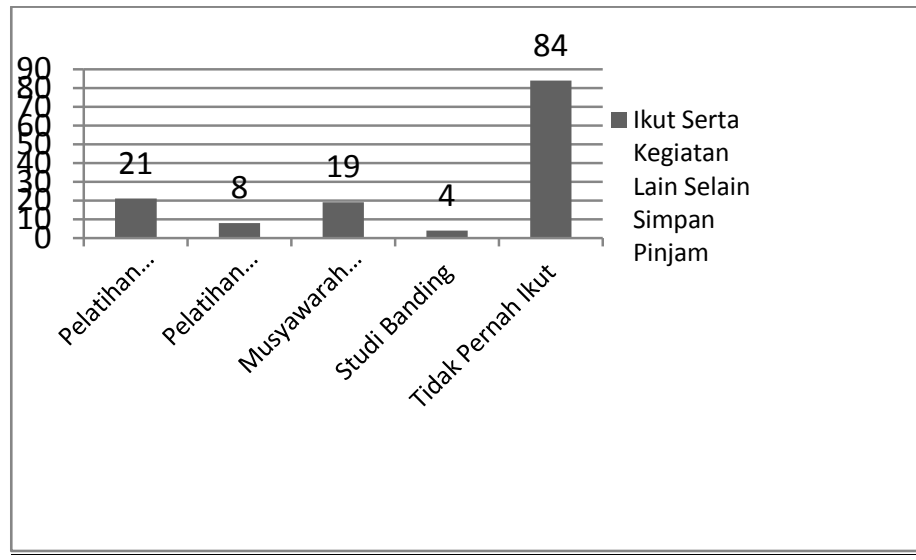

Grafik 11 Partisipasi Anggota dalam Kegiatan Pembangunan

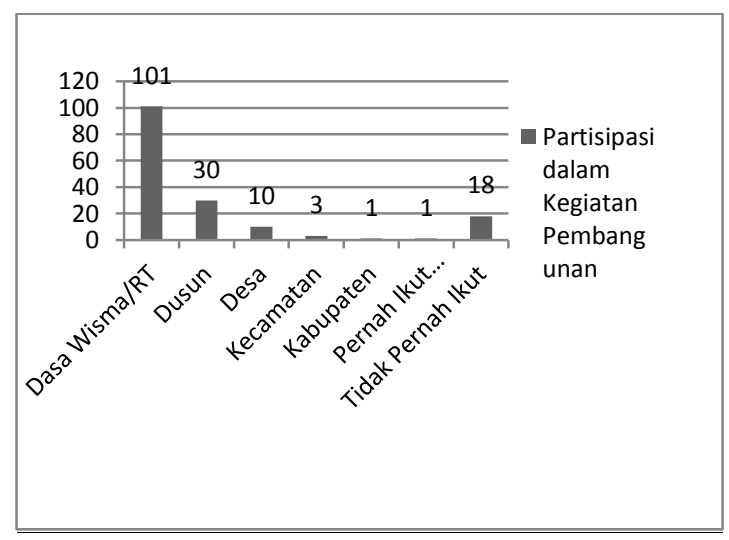

Mayoritas responden

$(84$

responden) belum pernah mengikuti kegiatan selain simpan pinjam. Sebanyak 21 responden pernah mengikuti pelatihan kewirausahaan, 19 orang mengikuti musyawarah desa dan 4 responden mengikuti mengikuti kegiatan studi banding. Mayoritas responden menyampaikan bahwa mereka tidak berpartisipasi dalam pelatihan kegiatan selain simpan pinjam karena tidak tahu, perwakilan kelompok saja dan biasanya ketua, dan kesibukan pekerjaan bagi responden yang setiap harinya harus berdagang. Akan tetapi kelompok dengan status pinjaman menunggak sampai 6 bulan yaitu kelompok Mekarsari, Kamijoro, Sendangsari semua anggota mendapatkan pelatihan kewirausahaan, pengembangan kelompok. Pelatihan tersebut berlokasi di rumah ketua kelompok.

Mayoritas responden kegiatan simpan pinjam perempuan PNPM Mandiri aktif di kegiatan dasa wisma/RT yaitu 101 responden. Tingkat keaktifan responden adalah sebuah rutinitas yang sudah dilakukan sebelum menjadi peserta kegiatan simpan pinjam perempuan PNPM Mandiri. Dan bahkan cikal bakal kemunculan kelompok berasal dari kegiatan RT. Informasi yang disampaikan dari UPK kepada pemerintahan desa tentang kegiatan simpan pinjam perempuan sampai kepada masyarakat selain melalui kegiatan sosialisasi di tingkat desa, juga tersampaikan melalui kegiatan RT. Sebanyak 30 
responden aktif di kegiatan dusun, 10 orang aktif di kegiatan desa. Responden yang aktif di kegiatan dusun dan desa biasanya menjadi penggerak kelompok dan menjadi pengurus kelompok seperti ketua, sekretaris ataupun bendahara, dan istri ketua RT.
Responden yang aktif di kegiatan kecamatan sebanyak 3 orang dan 1 orang aktif di kegiatan kabupaten. Responden yang tidak aktif di kegiatan apapun meskipun itu kegiatan RT terjadi karena kegiatan RT tidak aktif/vakum.

Grafik 12 Peningkatan Partisipasi Responden dalam Pembangunan

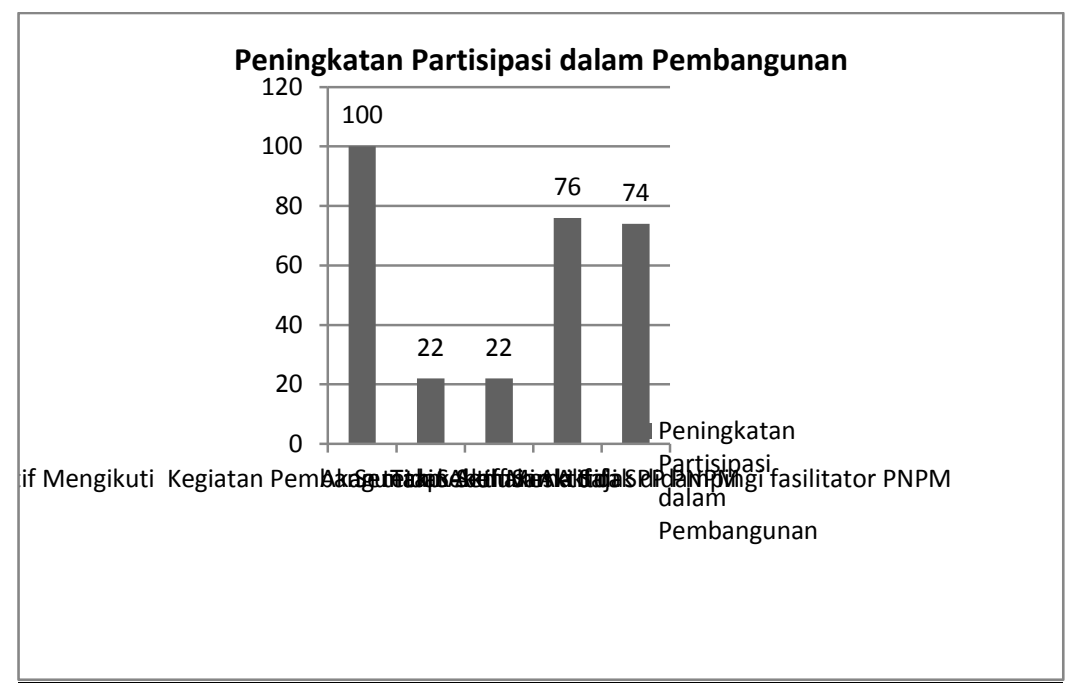

\section{Peningkatan Kemampuan Perempuan}

\section{dalam Mengelola Usaha}

Terkait dengan peningkatan kemampuan perempuan dalam mengelola usaha mayoritas responden (88) sudah memiliki usaha sebelum mengikuti kegiatan simpan pinjam perempuan. Sedangkan sejumlah 32 responden belum memiliki usaha. Peningkatan kemampuan yang paling signifikan terjadi pada responden yang memiliki usaha emping melinjo dan garut. Mayoritas responden dengan usaha emping melinjo dan garut sebelum mengikuti kegiatan simpan pinjam merupakan buruh thuthuk emping. Setelah mereka mendapatkan pinjaman rata-rata mampu membeli bahan baku sendiri. Akan tetapi

Grafik 13Kepemilikan Usaha Sebelum Mengikuti saat terjadi kemacetan pada pinjaman oleh sebagian anggota sehingga mereka belum bisa meminjam lagi, mereka kembali menjadi buruh thuthuk emping. Responden dengan jenis usaha emping melinjo dengan pinjam tidak terlalu banyak jika dikelola dengan benar juga mampu memperkerjakan sampai lebih dari 2 pekerja. Pada salah satu responden dengan jenis usaha batik kayu juga merasakan perubahan yang berarti dengan mengikuti kegiatan simpan pinjam. Sebelum mendapatkan pinjaman dia hanya menjadi buruh mewarnai batik kayu, setelah mendapatkan pinjaman dia bisa membeli pewarna sendiri.

\section{Grafik 14 Pelatihan Usaha yang Pernah Diikuti}


Kegiatan SPP PNPM

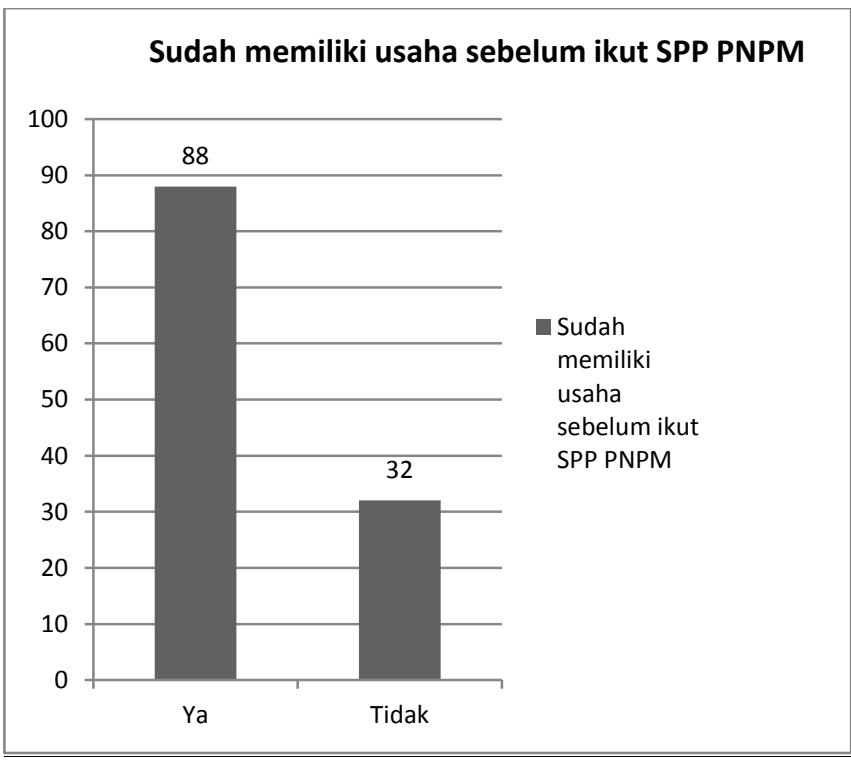

Pelatihan Usaha Kegiatan SPP PNPM yang Pernah diikuti

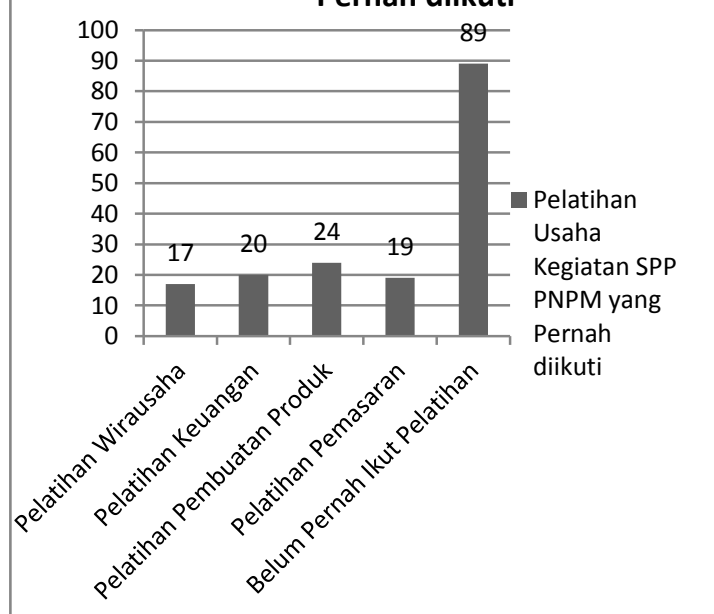

Upaya peningkatan kemampuan usaha juga dilakukan dalam bentuk pengadaan pelatihan kewirausahaan, pelatihan keuangan, pelatihan pembuatan produk, pemasaran dan studi banding. Sejumlah 17 responden sudah mengikuti pelatihan kewirausahaan, 20 orang mengikuti pelatihan keuangan,dan 24 orang melakukan pelatihan pembuatan produk dan 19 orang mengikuti pelatihan pemasaran. Dana mayoritas responden belum pernah mengikuti kegiatan pelatihan pengembangan kemampuan usaha.

\section{Simpulan}

Kegiatan pemberdayaan perempuan melalui simpan pinjam kelompok terbukti mampu memberikan berbagai perbaikan. Terjadi pengurangan keluarga miskin dengan penggunaan pinjaman sebagian besar untuk penambahan modal kegiatan usaha sendiri. Perubahan penghasilan dalam kapasitas sedang akan tetapi cukup mengubah kemampuan ekonomi perempuan menjadi bisa memegang uang sendiri tidak terlalu bergantung pada suami, mengubah dari buruh menjadi mempunyai usaha sendiri, mayoritas usaha masih dikerjakan sendiri. Terjadi peningkatan kemampuan perempuan dalam partisipasi pembangunan. Mayoritas responden aktif dalam kegiatan dasa wisma/RT dan akan tetap aktif tidak didampingi oleh fasilitator kegiatan SPP PNPM.

Tingkat partisipasi responden di tingkat dusun, kecamatan, dan kabupaten banyak dilakukan oleh responden seperti ketua RT, ketua kelompok. Keberadaan SPP PNPM membuat tingkat keaktifan di level dusun, kecamatan, dan kabupaten semakin aktif. Kegiatan simpan pinjam juga mampu meningkatkan kemampuan perempuan dalam pengelolaan usaha terlihat dari adanya mayoritas responden sudah 
memiliki usaha sebelum mengikuti kegiatan simpan pinjam kemudian menjadi mempunyai usaha serta keikutsertaan anggota mengikuti kegiatan peningkatan kapasitas usaha.

\section{Daftar Pustaka}

Ardiyati.2015. Strategi Keberlanjutan Implementasi Kegiatan Simpan Pinjam Perempuan (SPP) PNPM Mandiri Pedesaan di Kecamatan Pajangan Bantul. Thesis Master. tidak diterbitkan.Yogyakarta: Gadjah Mada University.

Asmorowati, Sulikah. 2005. Dampak Pemberian Kredit Mikro Untuk Perempuan: Analisis Pengadopsian Model Grameen Bank Indonesia, Surabaya: Jurusan llmu Administrasi Negara, FISIP Universitas Airlangga

Cernea, Michael M, 1986, Mengutamakan Manusia dalam Pembangunan:Variabelvariabel Sosiologi dalam Pembangunan Pedesaan (terjemahan), Ul Press, Jakarta. Kuncoro, Mudrajad. 2008. Pembiayaan Usaha kecil, Economic Review No. 211 Maret 2008

Suyanto. 1996. Perangkap kemiskinan: Problema dan strategi pengentasannya dalam Pembangunan Desa. Yogyakarta: Aditya Media.

Sedarmayanti. 2004. Good Governance (Kepemerintahan yang baik) Bagian kedua Membangun system Manajemen Kinerja Guna Meningkatkan Produktivitas Menuju Good Governance (Kepemerintahan yang Baik). Bandung: Penerbit Mandar Maju
Wardoyo dan Hendro Prabowo. 2005. Model Pengelolaan dan Pengembangan Usaha kredit Mikro Koperasi Warga Kusuma Tiara, Jakarta

Tjokrowinoto,Moeljarto.1997. Politik Pembangunan, Sebuah Analisis Konsep dan Strategis. Tiara Wacana, Yogyakarta.

Undang-Undang Republik Indonesia Nomor 2 tentang Sistem Pendidikan Nasional. 1990. Jakarta: PT. Armas Duta Jaya.

Unit Pelaksana Kecamatan (UPK) Kecamatan Pajangan. 2013. Laporan Kolektibilitas Pinjaman SPP UPK Kecamatan Pajangan bulan September 2013.Yogyakarta

Unit Pelaksana Kecamatan (UPK) Kecamatan Pajangan. 2013. Laporan Tahunan Kecamatan Pajangan tahun 20062012.Yogyakarta 